\title{
Pode uma imagem ser um argumento?
}

\section{Can the image be an argument?}

\section{Samuel Mateus}

Professor Doutor na Universidade da Madeira e investigador do Centro de Estudos de Comunicação e Linguagens (FCSHUNL). Autor de "Publicidade e Consumação nas Sociedades Contemporâneas" e "Tele-realidade: o princípio de publicidade mediatizado".

<samuelmateus@uma.pt>

\section{RESUMO}

Em sociedades dotadas de uma forte cultura visual, urge interrogar a legitimidade de estender a noção clássica e logocêntrica de "argumento", até domínios não discursivos ou linguísticos, como é o caso dos fenómenos visuais. Contribuindo para discussão lusófona acerca do potencial argumentativo das imagens, este artigo argui que, embora nem todas as imagens possuam uma forma argumentativa, tal não nos leva necessariamente a supor que nenhum argumento pode ser apresentado sob a forma visual. Admitindo a perspectiva verbalista do argumento visual, segundo a qual os argumentos visuais possuem uma natureza discursiva, salienta-se a importância das proposições visuais para a apresentação de conclusões e razões que as sustentem. A análise de um cartoon e o isolamento das suas proposições visuais fornece a oportunidade de demonstrar como, na vida quotidiana, podemos observar o funcionamento de um argumento visual.

\begin{abstract}
In societies like ours with a strong visual culture, it is urgent to question the legitimacy of extending the classical and rational notion of "argument", to nonlinguistic or non-discursive fields, as is the case of visual phenomena. Contributing to the lusophone debate about the argumentative potential of images, this article argues that although not all images have an argumentative form, it does not necessarily leads us to assume that no argument can be presented in a visual form. Admitting the verbalist perspective on visual arguments, according to which visual arguments have a discursive nature, the paper stresses the importance of visual propositions to the reason-giving process that characterizes argumentation. The analysis of a cartoon and the isolation of its visual propositions provides the opportunity to demonstrate how, in everyday life, we can observe how a visual argument works.
\end{abstract}

Keywords: Visual Rhetoric. Argumentation Theory. Communication.

Palavras-chave: Retórica Visual. Teoria da Argumentação. Comunicação.

\section{Introdução}

Que as imagens servem propósitos persuasivos sendo frequentemente utilizadas durante a argumentação parece ser um facto incontestável. $O$ desafio reside em compreender o seu funcionamento durante a esgrima logomáquica. Com efeito, uma das grandes preocupações actuais da Teoria da Argumentação é perceber o papel que os argumentos visuais (fotografias, cartoons, anúncios de publicidade, sátiras visuais, etc) desempenham no processo de argumentação (Johnson; Blair, 2000 e Blair, 2012a). Será que os objectos visuais limitam-se a ilustrar ou sintetizar a argumentação verbal, ou funcionam como verdadeiras 
teses verbais que procuram o assentimento do interlocutor (Aspeitia, 2012, p. 356).

Averiguar até que ponto as imagens podem, ou não, desempenhar um papel substancial na argumentação, assumindo uma função semelhante às palavras ${ }^{1}$, é a tarefa empreendida pela Retórica Visual. Este campo de estudos procura explicar a retórica para lá das fronteiras estritas do verbal explicando como funciona a persuasão visual. Foss, Foss e Trapp (1985), por exemplo, expandem o conceito de"retórica"em direcção à comunicação. A retórica é vista, pois, como a distintiva capacidade humana de utilizar símbolos para comunicar.

A Retórica Visual é a expressão utilizada para descrever o campo de estudo, dentro da retórica, que se ocupa da natureza e funcionamento dos fenómenos visuais dentro do processo abrangente de persuasão (Foss, 2004, p. 303). Uma das primeiras propostas anglófonas a abrir o campo da retórica às imagens ${ }^{2}$ foi a de Ehninger (1972) cuja definição de retórica não privilegiava os símbolos verbais englobando actividades simbólicas muito díspares como a dança, a arquitectura ou a arte $^{3}$. Kjeldsen (2015, p. 115) situa o ano de 1996 como o ano em que verdadeiramente tem início a pesquisa em torno da Argumentação Visual, com a publicação do artigo de Leo Groarke Logic, Art and Argument. Quer o campo da Retórica Visual, quer o da Argumentação Visual, assentam no princípio que a persuasão e a argumentação podem ser compreendidas como processos eclécticos cuja delimitação meramente verbal significa um espartilhamento do potencial de estudo reservado às iniciativas que ousem estender a retórica e a argumentação às práticas simbólicas visuais.

Se é verdade que, como afirma Jamieson (citado por Foss, 2004, p. 116), as imagens são particularmente susceptíveis ao truncamento do argumento e vulneráveis à emotividade, a necessidade de inclui-la nos estudos em torno da retórica e da argumentação é actualmente maior que nunca, por três motivos principais.

1 Como sabemos, a tradição ocidental identificou historicamente a argumentação com a razão e com o discurso verbal. No Górgias, Platão identifica a persuasão com a palavra e Aristóteles, na Retórica, coloca a linguagem verbal como o principal medium do orador. A própria noção de "Retórica" está intimamente ligada à dimensão logocrática. Para Reboul (1998, p. XIV), por exemplo, "a retórica é a arte de persuadir pelo discurso".

2 O texto Rhétorique de l'image de Roland Barthes, escrito em 1964, é também um percursor nesta área, e não podia deixar de ser mencionado.

3 A arte tem sido periodicamente utilizada como uma espécie de uma retórica de poder por parte dos governantes ao longo da história. O exemplo mais flagrante será o da civilização egípcia ou da civilização romana. Isto é perfeitamente visível no modo como o monarca ou o imperador se fazia representar na estatuária ou em baixos-relevos. 
Em primeiro lugar, a ubiquidade da imagem nas sociedades é incontornável sendo também um aspecto fundamental da cultura contemporânea. As imagens estão em todo o lado, seja na forma de perfis de redes sociais, seja em filmes, fotografias, televisão, ou internet. A própria publicidade (no sentido de Esfera Pública) reconhece aos símbolos não-verbais uma influência inaudita que não existia durante a chamada Esfera Pública Burguesa dominada pela imprensa e pela palavra (oral e escrita) (Habermas, 1991). Restringir o estudo da prática argumentativa e persuasiva apenas aos símbolos verbais significaria estudar somente uma pequeníssima parte dos processos comunicativos que todos os dias empreendemos.

Em segundo lugar, é necessário pensar a argumentação visual perante o reconhecimento de que as imagens visuais ${ }^{4}$ nos fornecem o acesso a uma compreensão da experiência humana que o mero discurso não permite. Experiência humanas que sejam dinâmicas, multilineares e intuitivas podem ser melhor captadas por símbolos não-discursivos (Foss, 2004, p. 117). A imediatez da tragédia estampada no rosto dos migrantes que tentam chegar à Europa através de uma travessia errante do Mar Mediterrâneo é mais facilmente conduzida por imagens do que por palavras que descrevam essa fatalidade.

Em terceiro lugar, ao envolver no símbolo outras manifestações que não apenas as verbais, estamos em condições de perceber melhor a dimensão comunicacional da persuasão e argumentação dando-nos uma perspectiva mais holística do processo de ganhar a adesão (Foss, 2004, p. 117). Alargar o campo de investigação da Retórica e da Teoria da Argumentação para lá da perspectiva discursiva será, assim, determinante numa avaliação compreensiva da comunicação persuasiva.

Mas, uma pergunta se impõe: $O$ que é um argumento visual? Podemos falar de argumentos visuais da mesma maneira que falamos de argumentos verbais? Até que ponto a palavra "argumento" mantém a sua dimensão logocrática, crítica e racional?

Neste artigo, procuramos contribuir para discussão lusófona de um campo de estudos bastante desenvolvido, balizando a ideia de argumento visual. Começaremos por debater o que está em causa na sua definição para, seguidamente, reflectirmos sobre a capacidade argumentativa da imagem, o carácter proposicional do argumento visual, concluindo com a identificação

4 "Imagem visual" pode parecer ao leitor redundante, mas a expressão é aqui utilizada em contraste com a imagem literária, a qual consiste na sobreposição de vários figuras-de-estilo como a metáfora, ou a alegoria. Damos como exemplo de imagem literária o verso "Gritam a Deus a bênção duma fonte", do poema de Florbela Espanca, intitulado "Árvores do Alentejo". 
das proposições visuais de um cartoon publicado pelo semanário português "Expresso".

Deste modo, visamos contribuir para o esclarecimento das fragilidades e potencialidades da ideia de "argumento visual", sublinhando o quanto algumas imagens são algo mais do que adjuvantes ou ornamentos da argumentação: são verdadeiramente elementos contribuidores para a configuração do processo argumentativo.

\section{Argumento visual: a imagem como veículo ou como forma expressiva}

O que está em causa na ideia de "argumento visual" é mostrar que a capacidade de argumentação não é exclusiva dos símbolos linguísticos. $\mathrm{Na}$ verdade, muitos argumentos verbais encontram a sua tradução visual em imagens (pensemos, por exemplo na propaganda política). Mas o que é exactamente o "argumento visual"?

A definição é tão óbvia quanto desprovida de polémica. De acordo com Birdsell e Groarke (2007, p. 103), "compreendemos por argumento visual os argumentos (no sentido tradicional de possuírem premissas e conclusão) que são veiculados através de imagens". Por outro lado, podemos considerar que a dimensão visual não é apenas ilustração da verbalização da forma argumentativa. Pelo contrário, a própria forma argumentativa pode ser desenvolvida visualmente. Por outras palavras, e de acordo com esta perspectiva, o argumento pode ser dotado de uma estrutura sintáctica intrinsecamente visual ${ }^{5}$.

A ideia de "argumento visual" contém, assim, duas possibilidades interpretativas: os argumentos visuais podem ser percebidos como argumentos transmitidos através de imagens; ou argumentos expressos de forma visual (Roque, 2010). Contudo, esta bifurcação conceitual não está isenta de ambiguidades.

Com efeito, na maior parte dos casos (anúncios publicitários, documentários de propaganda, etc) o argumento visual é formado num ambiente simbólico híbrido contendo, também, elementos verbais. À excepção de casos isolados, o argumento visual compõe-se de um código verbal e visual. Por isso, Roque (2010) propõe que o analisemos de acordo com um "sistema multi-código" (multi-code system). E, num sentido análogo, Aspeitia (2012) menciona a ideia de "argumentos heterogéneos": argumentos que não são conduzidos apenas por um medium mas que utilizam recursos, quer visuais, quer verbais.

5 A própria Semiótica Social se tem encarregado de explorar esta possibilidade. Vide Kress and van Leeuwen (1996). 
Um segundo nível de ambiguidades evoca sobretudo a definição de "visual". Roque (2010) chama a atenção para o facto da noção de "visual" poder referir duas situações perfeitamente distintas: por vezes, "visual" alude ao canal ou meio (medium) de transmissão, outras ao código visual. O canal de transmissão não é suficiente para definir um tipo especial de argumentação. Que o argumento seja convertido ou transmitido por imagens aponta, desde logo, para a pré-existência de uma forma verbalizada do argumento. Assim, não teríamos no "argumento visual" uma expressão propriamente visual do argumento mas um argumento verbal auxiliado por imagens. Teríamos somente uma argumentação que faz uso de dois canais diferentes. É quando consideramos o "visual" enquanto código que nos aproximamos de uma concepção original e essencialmente visual do argumento. Enquanto código, o visual assume um conjunto coordenado de regras que permitem dar sentido aos elementos de uma mensagem (Roque, 2010).

Contudo, mesmo ressalvando esta dupla ambiguidade (o visual como canal ou como código), permanecemos com uma questão fundamental: Qual é a especificidade da argumentação visual? E qual o seu significado do ponto de vista do plano heterogéneo do argumento que articula palavras e imagens no desenvolvimento do argumento? Necessitamos, assim, de equacionar as relações entre palavra e imagem na argumentação.

\section{Argumento e imagem visual}

Como vimos, uma dos pressuposições da Retórica e da Argumentação Visuais é preverem a possibilidade entidades não-linguísticas, como é o caso das imagens visuais, podem desempenhar um papel primordial na argumentação. A tarefa seguinte é inquirir a natureza desse papel e clarificar se a ideia de argumento na expressão "argumento visual" equivale ao sentido clássico e discursivo que tem dominado a Retórica e a Teoria da Argumentação. De acordo com Birdsell e Groarke (2007, p. 103) os argumentos visuais podem ser compreendidos e analisados através dos elementos clássicos da retórica (por exemplo, o ethos, pathos ou logos).

A possibilidade da palavra "argumento" ser pertinente do contexto da Retórica Visual tem sido objecto de um disputadíssimo (e estimulante) debate: temos, por um lado, os autores que consideram que a argumentação é um processo lógico e cognitivo e, por isso, independente de qualquer forma de expressão (seja verbal ou visual) (Schwed, 2007; Kjeldsen, 2015). E, por outro lado, autores que a dimensão visual corresponde a uma forma de expressão argumentativa completamente diferenciada e que defendem que falar de 
"argumento", nestes casos, corresponde a colocar um peso e uma conotação que a palavra não possui no seu sentido convencional. Estes autores tendem, pois, a rejeitar que as imagens possam ser argumentos (Johnson, 2003, Fleming, 1996).

Em Can Pictures be Arguments?, David Fleming (1996, p. 11) recorda que a palavra "argumento" tem sido objecto de considerável apropriação e ampliação. Com efeito, uma pintura, um grafiti ou uma fotografia pode influenciar os indivíduos e o seu sistema de pensamento. Mas será que argumentam? Fleming (1996) argui que a associação do conceito de argumento às imagens acarreta o risco de perder a essência da compreensão convencional da palavra. Também Anthony Blair (2012b) salienta os perigos de um alargamento excessivo da utilização do conceito.

\footnotetext{
Se se usar a palavra "argumento» noutro sentido, um que não esteja relacionado com raciocinar (reason-having) e dar razões (reason-giving) (...) então, perder-se-á contacto não apenas com o modo como academicamente se percebe a argumentação, como também com o modo como o conceito de argumento funcionou historicamente (...) Nesse caso, estar-se-ia a falar de outra coisa que não o sentido estipulado do conceito (Blair, 2012b, p. 265).
}

De acordo com Fleming (1996), existe um conjunto de pressupostos no entendimento clássico da noção de "argumento" que não são satisfeitos pelas imagens. E deste modo, as imagens não poderão ser argumentos (pelo menos, no sentido clássico).

Comecemos por um princípio fundamental do pensamento ocidental: um argumento é composto por duas partes, uma tese e a apresentação de dados que apoiem e justifiquem essa tese (conclusão e premissas). Perelman e Olbrechts-Tyteca (2000) ressaltam este aspecto ao afirmar que o objectivo da argumentação é transferir para a conclusão a adesão do auditório concedida às premissas. Mas, para Fleming (1996), as imagens não dispõem dessa capacidade de articular tese e justificação (reason-claim). Elas podem apresentar ou expressar ideias, contudo, não as podem afirmar (Fleming, 1996). De acordo com o autor, as imagens não dispõem do ordenamento interno linear que caracteriza o discurso verbal. Goodman (1978) concorda: o não-verbal pode exemplificar, mas não pode denotar. "Em si, uma imagem é desprovida de sintaxe sequencial e, portanto, incapaz de ordenar ideias numa estrutura conceptual de argumentação composta por duas partes" (Fleming, 1996, p. 114). 
Desacompanhada pela linguagem verbal, a imagem é incapaz de articular uma tese e justificação, não conseguindo funcionar de forma independente como uma afirmação (assertion).

Por outro lado, Fleming (1996, p. 116) afirma que às imagens falta outra característica central do argumento: o facto de possibilitar afirmações contrárias. Na sua forma discursiva, o argumento permite a diferença fazendo da controvérsia e polémica os seus princípios primordiais. Numa argumentação, temos de escolher entre dois lados por vezes antagónicos. O desacordo é uma possibilidade intrínseca à apresentação de motivos e justificação de opiniões. Numa palavra, o argumento é sempre discutível. Contudo, Fleming (1996) cita Worth para afirmar que as imagens, ao contrário, da linguagem verbal, não conseguem lidar com a negação. Podemos dizer o que uma imagem não é, mas não existe modo de uma imagem afirmar que não é. "À imagem falta a distância da realidade e do contexto histórico que nos permite negá-la" (Fleming, 1996, p. 116). A refutabilidade é, assim, outro critério que Fleming avança para distanciar a imagem da argumentação e da racionalidade. Na verdade, "uma imagem não apresenta nenhuma tese (claim) que possa ser contestada, duvidada ou melhorada pelo contributo de outros" (Fleming, 1996, p. 115).

Blair (2012a) sintetiza a sua relutância em torno do argumento visual da seguinte forma: "Para que um argumento seja considerado como tal tem de apresentar razões e justificações. Além disso, tem de afirmá-las claramente de modo a que possa ser aceito ou rejeitado" (Blair, 2012a, p. 208).

De acordo com esta perspectiva, argumentar é, sobretudo, dar razões (reasoning) e debater uma conclusão. Algo que não possa ser decomposto em tese e justificação ou que não possa ser contestada e refutada cai fora do âmbito (tradicional) da argumentação. Uma imagem só pode ser considerada um argumento se por "argumento" tivermos um critério tão largo que quase o desfigura do seu significado filosófico (Fleming, 1996, p. 117). Se as imagens visuais, sem o apêndice discursivo, não podem reivindicar alguma coisa da realidade (make a claim), isto significa que elas apenas podem funcionar como apoio a uma reivindicação (claim) linguística. O facto das teorias convencionais da argumentação associarem o argumento a um tipo particular de acto discursivo, faz com que Fleming defenda que as imagens não podem argumentar (Fleming, 1996, p. 117).

\section{Argumento: palavra e imagem}

Ao relembrarmos a proposta de Fleming de que as imagens não argumentam (no sentido crítico e discursivo que o pensamento ocidental 
Ihe emprestou) não estamos a afirmar que a Retórica Visual ou o Argumento Visual sejam objectos menores que não mereçam ser estudados. Pelo contrário, merecem ser investigados no sentido do "argumento heterogéneo" (Aspeitia, 2012), na cumplicidade entre palavra e imagem. Algumas imagens dificilmente se coadunam com o argumento tido como a proposta de teses razoáveis e justificáveis. No entanto, são elementos fundamentais no processo argumentativo. Cabe, então, definir a natureza da influência das imagens visuais junto da argumentação.

Apesar de muito pertinentes, as críticas de Fleming (1996), não autorizam uma negação categórica do poder argumentativo das imagens. Se reconhecermos na imagem visual a apresentação e justificação de ideias, então, de acordo com os critérios enunciados por Fleming (1996), podemos aceitar que as imagens não apenas argumentam, como são (potencialmente) argumentos. Elas podem eventualmente articular-se com a palavra ao ponto de imagem e palavra criarem uma forma argumentativa poderosa que sintetiza a autenticidade do visual com o raciocínio crítico da linguagem verbal. Este papel não é secundário. Ainda que a imagem, tendencialmente, não tenda a argumentar por si só, ela é um poderoso aliado da argumentação discursiva. Entramos, assim, numa das mais discutidas questões: a dimensão proposicional do argumento visual. Em que medida os argumentos visuais apresentam proposições, isto é, declarações acerca da realidade detentoras de valor de verdade?

Aceitar a sua proposicionalidade implica, antes de mais, reconhecer que as imagens visuais possuem as mesmas características que os símbolos discursivos. Trata-se de estudar a Retórica Visual de acordo uma teoria discursiva. "Os argumentos visuais devem ser percebidos como argumentos proposicionais nos quais as proposições e a sua função argumentativa é expressa visualmente" (Blair, 2012a, p. 209).

Segundo Groarke (2007), Johnson (2003) ou Fleming (1996), os argumentos são constituídos por proposições. E as frases ou elementos verbais que os compõem são a melhor maneira de representar e desenvolver um argumento. A esta perspectiva Tseronis (2013) chama de "verbalismo" (verbalism). Deste modo, a existência e utilização de argumentos visuais centrase na possibilidade das imagens visuais serem reduzidas a equivalentes verbais. Como se percebe, o verbalismo reitera a ideia de que as imagens visuais funcionam, na argumentação, como suporte ou de acordo com a reivindicação 
linguística ${ }^{6}$. O verbalismo pensa, assim, os argumentos visuais do mesmo modo que pensa as palavras.

Tudo o que precisamos para identificarmos argumentos visuais a partir de proposições expressas visualmente (proposições visuais) é podermos comunicar visualmente as funções dessas proposições, de modo que se possa comunicar que algumas proposições visuais são reivindicações (claims) e outras proposições são razões (reasons) para essas reivindicações" (Blair, 2012a, p. 209).

Blair é peremptório ao afirmar que

[...]os argumentos visuais não são essencialmente distintos dos argumentos verbais. $O$ argumento é sempre uma entidade proposicional que apenas é expressa de maneira diferente. Portanto, os argumentos visuais não são uma estimulante novidade conceptual; eles não constituem um campo de argumentação radicalmente diferente (Blair, 2012a, p. 223).

Tal não significa que devamos abdicar da expressão "argumento visual". Aponta, antes, para a premência de localizarmos nas imagens as suas proposições visuais. Na verdade, o que distingue o argumento visual de outras formas de persuasão visual é que, no primeiro caso, é possível avançar razões que sustentem uma tese (Blair, 2012 b).

De seguida, discutimos como um cartoon pode ser analisado do ponto de vista de um argumento visual. Deste modo, demonstramos como as propostas da perspectiva verbalistas do argumento visual podem ser identificadas num dos mais prosaicos objectos visuais contemporâneos.

\section{Proposições visuais: análise de um cartoon}

De acordo com o que temos escrito, uma imagem é inerentemente proposicional na medida em que carrega informação que é alegadamente verdadeira (Birdsell e Groarke, 2007). O percurso desenhado numa folha de papel é um exemplo de uma imagem visual que supostamente é uma representação verdadeira e suficientemente exacta do ordenamento urbano do bairro onde o turista se perdeu. Metáforas visuais e símbolos são frequentemente usadas para transmitir proposições, especialmente no debate político.

6 Uma das críticas comuns apontadas ao verbalismo passa por afirmar (Foss, 2004) que as imagens visuais expressam proposições mas de um modo completamente distinto das proposições verbais. De acordo com esta crítica, o que autores do verbalismo se esquecem é de considerar que as imagens visuais são proposicionalmente idênticas às formas verbais apenas porque as verbalizamos. 
A Figura 1 fornece-nos um exemplo muito interessante de uma imagem visual que contém várias proposições incrustadas. Repare-se que não existe aqui nenhuma referência verbal. Os elementos visuais não são redundantes face aos elementos verbais implícitos. Sem qualquer legenda ou palavra (exceptuando a forma abreviada de "Portugal" que aparece no jornal), o cartoon é vago e ambíguo. É a partir do momento em que identificamos as suas proposições verbais implícitas que ele adquire um sentido muito particular. E essa é uma grande diferença em relação aos argumentos verbais: enquanto nesses as proposições são afirmadas de forma explícita, nos argumentos visuais as teses são reiteradas de forma subentendida e colocadas sob um manto de códigos visuais simbólicos que necessitam de ser descodificados.

- “Figura 1"- Cartoon publicado no semanário “Expresso"

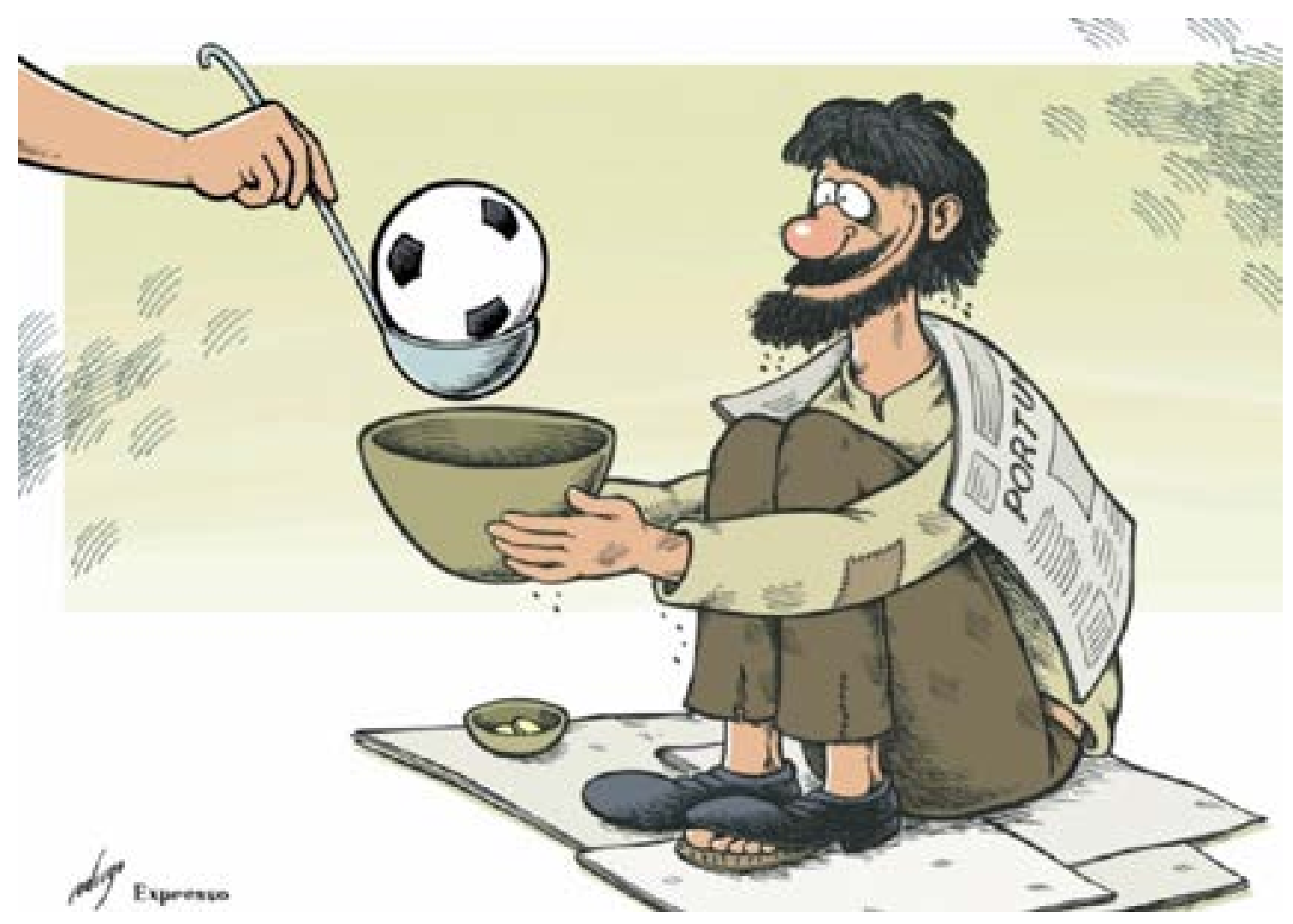

Fonte: Matos, 2013.

Mas, pode a Figura 1 ser considerada um argumento visual? A imagem possui um teor político e um laivo de sátira que torna plausível a ideia de que pretende fazer aceitar um ponto de vista particular sobre a situação política e social de Portugal em tempos de austeridade financeira por parte do Estado. 
E embora possa ser visual, a verdade é que encontramos aqui o mesmo mecanismo de apresentar motivos que sustentam uma tese que Fleming associa ao argumento (Fleming, 1996). Na medida em que argumentar é, sobretudo, pensar e contender uma conclusão, esse cartoon assume a forma de um argumento visual podendo ser dividido em tese e justificação.

Façamos, então, o exercício de o decompor em proposições verbais. Isso não quer dizer que os significados visuais e verbais sejam equivalentes ou que as imagens e as palavras transmitam rigorosamente os mesmos significados. O que pretendemos é identificar as proposições visuais, as quais, segundo a interpretação verbalista do argumento visual, podem ser reconhecidas em proposições discursivas.

O argumento visual assume, então, a seguinte proposta: "Portugal é um país pobre que vive à custa do futebol". Eis, portanto, a tese que é preciso justificar. O cartoon avança, assim, algumas proposições visuais que visam suportar a enunciação discursiva: (i) na medida em que está dependente da ajuda financeira de terceiros, Portugal vive numa situação comparável à mendicidade (ii) o que alimenta o ânimo de Portugal é o desporto futebolístico (iii) decorrente da proposição anterior, encontramos: o cidadão português passa dificuldades mas sente-se satisfeito por, pelo menos, possuir a alegria do futebol.

Cada proposição verbal encontra-se implícita sendo por isso representada respectivamente por um conjunto de símbolos: (i) uma tigela com esmolas ao lado do indivíduo e roupas andrajosas; (ii) a colher onde habitualmente se serve a sopa contém uma bola de futebol que é servida ao indivíduo; (iii) o sorriso na sua boca perante a oferta da bola de futebol para a sua tigela. Cada um destes símbolos justifica o argumento avançado. A tese de que "Portugal é um país pobre que vive à custa do futebol" está, deste modo, reforçada: "Portugal é pobre pois vive como um mendicante sobrevivendo, com resignação satisfeita, através do futebol".

O jornal nas costas do mendigo (onde é possível aferir "Portugal" a partir da palavra incompleta "Portu") é outro elemento simbólico central desse argumento visual. Por um lado, diz-nos que a situação reivindicada não diz respeito a qualquer cidadão do mundo, mas muito particularmente aos portugueses. Por outro lado, veicula essa informação através da utilização de um jornal impresso (podia facilmente ter incluído uma legenda, um cartaz ou as cores nacionais para nos dar esse esclarecimento). Por que o jornal? Talvez porque, no imaginário ocidental, a imprensa (e os media em geral) são acreditados com a transmissão credível, objectiva e rigorosa dos acontecimentos do mundo. $\mathrm{O}$ jornal funciona, nesse exemplo, não apenas como suporte da informação con- 
textual a que o argumento visual diz respeito, como também como símbolo de uma opinião verossímil e exacta acerca do mundo. A sua inclusão no cartoon não é fortuita. Ela funciona como um verdadeiro mecanismo retórico: o de gerar persuasão. Esta persuasão é conseguida por um tipo de argumento muito utilizado desde a antiguidade: argumentum ad verecundiam ou argumento de autoridade, em que a validação da conclusão é conseguida através do recurso à credibilidade de uma pessoa ou instituição. Nesse caso particular, o argumento de autoridade incrustado no argumento visual recorre ao prestígio que os media possuem nas sociedades contemporâneas para reforçar a autenticidade e crédito desta perspectiva crítica acerca da situação económica e social de Portugal. Com efeito, uma das crenças associadas aos Media que corrobora a sua credibilidade é a sua função de "espelhos" da realidade (ex: The Daily Mirror).

Saliente-se que esse mecanismo persuasivo contido no argumento visual é conseguido através de uma mise-en-abyme que duplica a credibilidade do argumento: não só, a imprensa é representada visualmente, como igualmente o argumento visual é difundido e tornado público através de um título de imprensa, o semanário Expresso. Fica, pois, claro que o argumento visual contido no cartoon contém elementos persuasivos que concorrem para reforçar a tese apresentada e fortalecer o argumento visual.

Complexificando a análise do argumento visual, podemos aludir a duas estruturas arquetípicas sugeridas pelo cartoon: por um lado, "a sopa dos pobres"; por outro lado, a sátira política de Juvenal sob a forma de panem et circenses. A "sopa dos pobres" traduz-se pela prática milenar de caridade e solidariedade através da qual se oferece uma refeição quente gratuita. Momento central do dia do sem-abrigo, esta oferta regular de alimento permite combater a fome. A expressão "sopa dos pobres" é, por isso, frequentemente utilizada em contextos de extrema pobreza e fragilidade social. Nesse caso, o "pão nosso de cada dia" é metaforicamente transformado numa bola de futebol, metonímia para o desporto.

Panem et Circenses, pão e circo, é a forma metonímica para um modo superficial de apaziguamento social. No campo da política, a expressão "pão e circo" é usada para descrever um meio de obtenção de aprovação pública através de uma aposta no entretenimento e distracção. É considerada como um eficaz paliativo para uma situação social grave na qual as tensões económicas e políticas respondem ao contexto de uma crise fundamental. Nas Sátiras de Juvenal, a expressão é utilizada de forma desdenhosa para retractar a erosão dos deveres cívicos e a sua substituição pela fruição fácil e gratuita. Transpondo esta estrutura para o nosso cartoon, encontramos o mesmo tipo de crítica 
social feita por Juvenal. O argumento visual contém, deste modo, uma estrutura argumentativa e uma estrutura satírica. Ambas as dimensões são discerníveis pela capacidade de enunciar verbalmente as proposições que suportam a tese.

A dimensão satírica aqui presente aponta para a escolha fácil que o cidadão português faz entre política e desporto. Esmiuçando o argumento encontramos: perante as dificuldades económicas e sociais, o individuo preocupa-se menos em debater essa situação do que fruir alegremente da recreação e evasão que o futebol lhe permite. A crítica subjacente (que não é respondida na imagem visual) é a da pertinência ou razoabilidade dessa opção pela evasão numa altura em que o futuro de Portugal (mais exactamente, a sua viabilidade financeira e económica) é tão incerto e discutido?.

Existe, ainda, outro mecanismo retórico da imagem: o destaque concedido ao auditório, cabendo-lhe aferir justamente a pertinência dessa crítica. Ele deve aceitar a tese proposta, mas deve igualmente avaliá-la tal como um auditório reagindo a um argumento enunciado de forma verbal.

As proposições visuais deste cartoon alegam que esta perspectiva crítica da situação económica e social de Portugal é verdadeira. Isto não significa que não possa ser rebatida. Mas terá de ser rebatida por argumentos verbais (ou eventualmente outra imagem). Como vimos, as imagens não podem ser refutadas no sentido de que conseguem afirmar o seu contrário. Porém, os argumentos visuais podem ser contestados exactamente porque na sua constituição apresentam proposições, as quais, de acordo com a proposta verbalista, funcionam de modo discursivo.

O cartoon do Expresso permitiu-nos, assim, investigar um argumento visual que praticamente dispensa elementos verbais, comprovando que as imagens visuais podem assumir uma forma proposicional. $E$ o que precisamente nos ajuda a compreender o argumento visual é a possibilidade da sua verbalização, isto é, o de assumir proposições discursivas implícitas nas proposições visuais.

Em síntese, o argumento visual aqui contido explana-se da seguinte maneira: "Portugal é um país pobre que vive à custa do futebol" que, à luz de uma perspectiva satírica (afinal, trata-se de um cartoon político), se desdobra no sub-argumento: "Perante as dificuldades económicas e sociais, os portugueses

7 Embora não conseguíssemos determinar a data de publicação do cartoon, ele é suficientemente recente para o podermos contextualizar com o programa de austeridade, negociado com a Troika, ter sido anunciado a 6 de abril de 2011, pelo então Ministro das Finanças, Teixeira dos Santos. Ainda que não possamos desenvolver a importância do contexto da argumentação, sublinhamos que Birdsell e Groarke (2007, p.111) propõem uma tipologia de contextos para avaliar o argumento visual, confirmando a necessidade de incluir as formas contextuais na análise argumentativa. 
preocupam-se menos em debater essa situação do que fruir alegremente da recreação e evasão que o futebol lhes permite".

\section{Conclusão}

Em The Rhetoric of Visual Arguments, Blair (2012b, p. 264) comenta algo que, por vezes, negligenciamos: nem todas as influências sobre as decisões e acções humanas podem ser consideradas argumentos, tal como nem todos os casos de persuasão envolvem formas argumentativas. Há, assim, que separar a argumentação de outras formas de exercício simbólico e aplicar esta distinção primordial entre persuasão e argumentação às imagens visuais. Embora as imagens possam argumentar (como exemplificámos), isso não nos leva a supor que a imagem contém uma impossibilidade ínsita à argumentação. Esta ideia é, aliás, o fundamento tanto da Retórica Visual quanto da Argumentação Visual.

Neste artigo procurámos clarificar as fronteiras que definem o argumento visual e a possibilidade das imagens funcionarem como argumentos. Não obstante, as alegações de Fleming (1996) de que as imagens não podem conter argumentos, foi nossa intenção demonstrar, a partir dos critérios que o autor indica, que, pelo menos, algumas imagens funcionam de acordo com um registo argumentativo procurando fazer assentir determinada tese e indicando um conjunto de asserções e razões que visam reforçar essa tese. Mesmo se a noção filosófica de "argumento" está envolta no véu discursivo, na prática, não existe, nas imagens, uma impossibilidade intrínseca que iniba uma forma argumentativa capaz de reivindicar (claim), fazer valer uma tese ou afirmar um determinado ponto de vista. Relembre-se que o que distingue o argumento visual da persuasão visual é precisamente a possibilidade de enunciar (o que corresponde a um verbalização) razões e motivos que sustentem uma tese (Blair, 2012b, p. 270).

Como arguimos, um início de resposta (embora não a definitiva) a esta questão passa por admitir uma perspectiva verbalista do argumento visual, segundo a qual os argumentos visuais possuem uma natureza verbal. A grande vantagem desta proposta consiste em permitir que se isolem algumas proposições visuais. Ao reconhecer as proposições visuais como estando equiparadas às proposições verbais, o caminho em direcção à argumentação fica aberto, já que a natureza verbal da proposição verbal acolhe a possibilidade de afirmar (asserting), reivindicar e declarar uma perspectiva acerca do mundo. E é justamente essa verbalização do argumento visual que pode ser contestada: não a imagem em si, mas a sua natureza proposicional. 
Um segundo início de resposta que evidenciámos ao longo do artigo passa, então, pelas proposições verbais. As imagens gozam de um poder evocativo que as palavras não alcançam (nem mesmo com a hipotipose), o qual poderá ajudar a perceber como se processa o encadeamento das proposições visuais.

A análise realizada à imagem publicada no jornal "Expresso" manifesta um conjunto de proposições visuais que parecem suportar um argumento. Ela envolve um encadeamento de premissas que concorrem para a conclusão. O raciocínio (reasoning) tão caro à argumentação verbal pode não assumir o protagonismo da palavra ao realizar-se por intermédio do visual. Todavia, não se encontra ausente desta imagem. Pelo contrário, podemos falar em argumento visual, neste caso particular, na medida em que somos capazes de retirar um conjunto de proposições visuais (obviamente orientadas por um valor de verdade) que subentendem a argumentação e a afirmação "razoável" de uma tese.

Nesta reflexão, pretendemos somente sublinhar que é esta natureza proposicional que nos autoriza a falar em argumento visual e que todos os dias convivemos com esses "argumentos heterógeneos" de que fala Aspeitia (2012). A imagem e a palavra cruzam-se, mesmo quando estamos perante imagens que contêm apenas proposições visuais. O argumento visual ou pictórico não substitui hoje, em sociedades caracterizadas por uma forte cultura visual, o argumento verbal. O que assistimos actualmente é à revelação, perpetrada pelos numerosos estudos de Retórica e Argumentação Visual, da interpenetração da dimensão verbal e visual da argumentação.

Uma imagem pode ser um argumento? — é o título desta reflexão. Dir-seia pelo exposto que nem todas as imagens contêm uma forma argumentativa. Algumas imagens de anúncios publicitários poderão assentar, sobretudo, num dispositivo persuasivo. Porém, algumas imagens visuais - como o cartoon examinado-poderão conter essa índole argumentativa onde se oferecem razões (premissas) que comprovem uma conclusão.

\section{Referências}

ASPEITIA, A. A. Words and images in argumentation. In: Argumentation, v. 26. p. 355368, 2012.

BIRDSELL, D. ; GROARKE, L. Toward a theory of visual argument. In: Argumentation and Advocacy, v. 33, n. 1, p. 1-10, Summer, 1996. 
Outlines of a theory of visual argument. In: Argumentation and Advocacy. V. 43, n. 3-4, p.103-113, Winter - Spring , 2007.

BLAIR, J.A. The possibility and actuality of visual arguments. In: Groundwork in the Theory of Argumentation, cap. 16, p. 205-223, 2012a. Amsterdam: Springer Publications. Originally published in Argumentation and Advocacy, V. 33, n.1, p. 23-39, Summer, 1996.

.The rethoric of visual arguments. In: Blair, J. A. Groundwork in the Theory of Argumentation, cap. 19, p. 261-279, 2012b. Amsterdam: Springer Publications. Originally published in C.A. HILL \& HELMERS. M. Defining Visual Rhetorics. Mahwah, New Jersey, London: Laurence Erlbaum Associates, p. 41-62, 2004.

EHNINGER, Douglas. Contemporary Rethoric: a reader's coursebook. Glenview: Scott Foresman, 1972.

FLEMING, David. Can pictures be arguments? In: Argumentation and Advocacy, v. 33, n.1, p. 11-22, Summer, 1996.

FOSS, S. K. ; FOSS, K.; TRAPP, R. Contemporary Perspectives on Rethoric. Propect Heights: Waveland Press, 1985.

FOSS, S. K. Framing the study of visual rhetoric: Toward a transformation of rhetorical theory. In: HILL, C.A.; HELMERS, M., Defining visual rethorics. London: Routledge, p. 303-313, 2004.

GOODMAN, N. Ways of worldmaking. Indianapolis: Hackett, 1978.

GROARKE, L. Beyond words. Two dogmas of informal logic. In: HANSEN, H. V. ; PINTO, R. C. Reason Reclaimed: Essays in Honor of Blair, J. A. ; Ralph H. Johnson. Newport News: Vale Press, p. 135-151, 2007.

HABERMAS, Jürgen. The Structural Transformation of the Public Sphere: An Inquiry into a category of Bourgeois Society. Massachusetts: MIT Press, 1991.

JOHNSON, R. H. Why "visual arguments" aren't arguments. In: INFORMAL LOGIC AT 25, 2003, Windsor, ON. Proceedings... Windsor: University of Winsor, CD-ROM, p.1-13, 2003.

; BLAIR. J.A. Informal logic: an overview. In: Informal Logic, v. 20, n. 2, p. 93-107, 2000.

KJELDSEN, J. The Study of Visual and Multimodal Argumentation. Argumentation. $V$. 29, n.2, p. 115-132, 2015.

KRESS, G. R.; van LEEUWEN, T. Reading Images: the grammar of graphic design. London: Routledge, 1996.

MATOS, Rodrigo. Futesmola. Jornal Expresso, 25 nov. 2013. Disponível em: < $\underline{\text { http:// }}$ 
www.publico.pt/culturaipsilon/noticia/cartoonista-rodrigo-de-matos-venceugrande-premio-press-cartoon-europe-1623649> . Acesso em: 30 jul. 2015.

PERELMAN, C. ; OLBRECHST-TYTECA, L. Tratado da Argumentação. Lisboa: Edições Piaget, 2000.

REBOUL, O. Introdução à Retórica. São Paulo: Martins Fontes, 1998.

ROQUE, G. Visual Argumentation. In: INTERNATIONAL SOCIETY FOR THE STUDY OF ARGUMENTATION (ISSA), Amsterdam. Proceedings...Amsterdam, 2010.

SCHWED, M. Visual objects as part of a rational communication process. In: INTERNATIONAL CONFERENCE OF THE ONTARIO SOCIETY FOR THE STUDY OF ARGUMENTATION (OSSA), 2007: Dissensus and the Search for Common Ground, Winsor, ON. Proceedings... HANSEN, H. V. e outros. Windor, ON: University of Winsor, CD-ROM , p. 1-10, 2007.

TSERONIS, A. Argumentative functions of visuals: beyond claiming and justifying. In: INTERNATIONAL CONFERENCE OF THE ONTARIO SOCIETY FOR THE STUDY OF ARGUMENTATION (OSSA), 2010: virtues of argumentation: Proceedings ... Windor, ON: University of Winsor, p. 22-26, 2013.

Recebido em: 30/07/2015.

Aceito em: 07/10/2015.

Endereço do Autor:

Samuel Mateus <samuelmateus@uma.pt>

Universidade da Madeira. Faculdade de Artes e Humanidades. Gabinete 1.47. Campus Universitário da Penteada.

9020-105 - Funchal, Portugal 